\title{
KRIGING TECHNIQUES AND GIS FOR MANAGEMENT OF PHOSPHATE EXTRACTION AT HAGARIA DISTRICT, EGYPT
}

\author{
S. S. Ahmed, M. R. El Tahlawi, M. Z. Rashad and H. A. Saleem \\ Mining and Metallurgical Engineering Department, Faculty of \\ Engineering, Assiut University, Assiut, 71518, EGYPT. \\ Email: dr_sameh_mining04@yahoo.com Fax: +20 0882332553
}

(Received October 2, 2007 Accepted October 21, 2007)

\begin{abstract}
Ordinary Kriging (OK) and Indicator Kriging (IK) techniques were used in conjunction with Geographic Information System (GIS) to understand the spatial distribution and variation of the $\mathrm{P}_{2} \mathrm{O}_{5} \%$ and phosphate thickness at Hagraria district, Egypt. The aim is to aid mining engineers in identifying the best areas that have high and low values of $\mathrm{P}_{2} \mathrm{O}_{5} \%$ with their associated thickness in order to manage the extraction scheme. This paper illustrates how the kriging results can be interpreted easily when they are integrated with other geological and mining data using suitable Geographic Information System. Both OK and IK were examined with the available data from the study area to estimate the two variables affecting the quantity and quality of phosphate; Additional information such as geological feature, boundaries of the area and sampling locations were integrated with the Kriging results and a GIS software (ARC/GIS 9.0) has been used to create contour and sensitivity maps that delineate the relative magnitudes of the measurements recorded at the study area, so a better management of the phosphate extraction could be planned.
\end{abstract}

KEYWORDS: Ordinary Kriging, Indicator Kriging, Hagaria, $\mathrm{P}_{2} \mathrm{O}_{5} \%$, GIS.

\section{INTRODUCTION}

Management and planning of mining extraction requires a realistic and accurate estimation of ore reserves and a through understanding of the spatial distribution of the mineral-content of the ore in the developing site. Nowadays with the facilities provided from mining computer software's and application of Geostatistics techniques, the estimation could be as accurate as the planner aims. However, the implementation of these modern tools has to be done with sufficient data and in a logic way.

Phosphate ore is one of the principal mineral products of Egypt. Hagaria district is located near the Nile valley at eastern Mahamid region which also consists of another four prospected areas that are Sharawna, Oweiniya, Mussattah Yassin, and Qurayat [1].

The Phosphate rocks is part of the vast upper Cretaceous marine phosphorite basin and is used extensively, mainly as a source of phosphorus for fertilizers, and for manufacture of phosphoric acid and other chemicals [2]. The phosphate rocks can be classified according to its grade as follows: poor grade $\mathrm{P}_{2} \mathrm{O}_{5} \%$ ranges from 15 to 22 , medium grade $\mathrm{P}_{2} \mathrm{O}_{5} \%$ ranges from 22 to 27 , and rich grade $\mathrm{P}_{2} \mathrm{O}_{5} \%$ greater than 27 [3]. 
Thus, identifying the geographic distribution of $\mathrm{P}_{2} \mathrm{O}_{5} \%$ is critical for mining engineers and would help the mining designer or decision maker to select the mining method for extraction and production control.

\section{REVIEW OF KRIGING TECHNIQUE APPLICATIONS}

Kriging is the name given to a class of statistical techniques for optimal spatial prediction. It was originally developed in 1959 in meteorology, but in 1963 was adapted to the mining industry to assist engineers with making mines more profitable decisions. Since then, it has been adopted in many disciplines, including geology, agriculture, and the environmental sciences [4].

The following section demonstrates some literature review of the most recent applications of kriging in mining and some other related fields.

Indicator Kriging method was used for estimating the grade in the strongly skewed gold distribution at Perth, Western Australia. Two indicator kriged estimates were prepared, one using deciles thresholds (the IK1 estimate) and another using modified thresholds (the IK2 estimate). The IK1 estimates, which used grade thresholds based on the de-clustered sample deciles, was a poor estimator [5]. Simple kriging (SK) with varying local means; kriging with an external drift; and collocated co-kriging were used for incorporating a digital elevation model into the spatial prediction of rainfall: The techniques are illustrated using annual and monthly rainfall observations measured at 36 climatic stations in a $5000 \mathrm{~km}^{2}$ region of Portugal [6].

Local linear regression (LR), inverse distance weighting (IDW), ordinary kriging, simple kriging with a locally varying mean (SKlm) and kriging with an external drift were used to predict $\mathrm{NO}_{2}$ diffusion from point data, collected as part of the United Kingdom, SKlm provided the most accurate predictions based on the summary statistics of prediction errors from cross-validation [7].

Ordinary Kriging (OK) and lognormal kriging (LK) were used to map the spatial patterns of heavy metals and disjunctive Kriging (DK)was used to quantify the probability of heavy metal concentrations higher than their guide value, while Cokriging method was used to minimize the sampling density for $\mathrm{Cu}, \mathrm{Zn}$ and $\mathrm{Cr}$ [8].

Two dimensional kriging and co-kriging cross validation grade estimation results of the sample points were compared by using the data taken from Küre copper mine in Turkey and noted that the co-kriging technique estimates the variable with lower value variance than the ordinary kriging. Moreover, the co-kriging estimation variance decreases as the block dimension increases [9].

Kriging method was used to interpolate the content of feldspar in the entire granite deposit in order to characterize the saleable feldspar in a granite deposit, and they used the same method to calculate the quantity of feldspar [10].

The results of inverse distance, ordinary kriging and median indicator kriging estimation were compared in the iron ore deposit that includes examination of local estimates and data distributions and showed that, the kriging methods have improved the estimation compared with the inverse distance method, in the block data distributions and the pattern of local estimates. The median indicator kriging method is considered to provide a better way of estimating an element with a bimodal or strongly skewed distribution. Outlying assay values have less influence when using the median indicator kriging method [11]. Universal kriging was used to create the probabilistic 
map of carbon monoxide concentration (ppm) as one of air pollutants [12]. Universal kriging and disjunctive Kriging were used to map the soil contamination and the probability of exceeding of the upper permissible level [4].

An example of integrated kriging technique and GIS is found in the work done by Diodato and Ceccarelli (2004) [13], they used multivariate geostatistical technique of indicator kriging to detect and classify macro zones according to their tendency to soil degradation. Geographical Information System (GIS) is used to delineate the areas suited to soil degradation maps.

Geographical Information System technology was used as a data management platform and three different interpolation techniques; spline, inverse distance weighted and kriging were used to visualize the spatial distribution of rainfall data in space and time in order to estimate storm characteristics from rainfall observations obtained by any number of rain gages [14]. A combination of geologic and GIS models has been used to analyze the sample data to estimate tonnages and qualities of the coal beds [15].

The main objective of this paper is to interpolate $\mathrm{P}_{2} \mathrm{O}_{5} \%$ and thickness at an un-sampled location based on surrounding measurements, and then plot these magnitudes on prediction maps to determine the best area that can start with it. In order to do this, Ordinary and indicator kriging were used for grade estimation at the mining area of Hagaria, and GIS was used to enhance the characterisation and display of resulting maps together with the other data.

\section{PRINCIPLES AND METHODOLOGY}

Kriging is one of the techniques employed to analyse continuous data and is defined as "interpolation with geostatistics" (Burrough and McDonnell 1998) [16]. Interpolation by Kriging is widely accepted by statisticians and scientists because the process is grounded on theory.

Many Kriging techniques exist and become available through much software's such as; GSLIB, Geostat, ArcView, ArcInfo, Surfer and many others. It is beyond the scope of this paper to explain the different kriging techniques however; the following are the main principles of the two types that are used in this research.

\section{Ordinary Kriging (OK)}

In Ordinary Kriging, points are interpolated using local mean values and prediction weights are based on the fitted variograms model. Ordinary Kriging assumes that the mean is known or that the data have been de-trended. The estimation variance is:

$$
\begin{aligned}
\boldsymbol{\sigma}_{\boldsymbol{E}}^{2} & =\boldsymbol{E}\left[\left(\boldsymbol{Z}^{*}\left(\boldsymbol{X}_{\mathbf{o}}\right)-\boldsymbol{Z}\left(\boldsymbol{X}_{\mathbf{o}}\right)\right)^{2}\right] \\
& =-\gamma\left(X_{0}-X_{0}\right)-\sum_{\alpha=1}^{n} \sum_{\beta=1}^{n} \omega_{\alpha} \omega_{\beta} \gamma\left(X_{\alpha}-X_{\beta}\right)+2 \sum_{\alpha=1}^{n} \omega_{\alpha} \gamma\left(X_{\alpha}-X_{0}\right)
\end{aligned}
$$

Where, $\sigma_{E}^{2}$ is the estimation variance, $\mathrm{E}$ is the estimation error, $\mathrm{Z}^{*}\left(\mathrm{X}_{0}\right)$ is the estimated value at location $\mathrm{X}_{0}, \mathrm{Z}\left(\mathrm{X}_{0}\right)$ is the true value, $\gamma\left(\mathrm{X}_{0}-\mathrm{X}_{0}\right)$ is the variogram, $\left(\omega_{\alpha} \& \omega_{\beta}\right)$ are the weights and $\left(X_{\alpha} \& X_{\beta}\right)$ are the neighboured samples. 
By minimizing the estimation variance with the constraint on the weights, the ordinary kriging system is obtained:

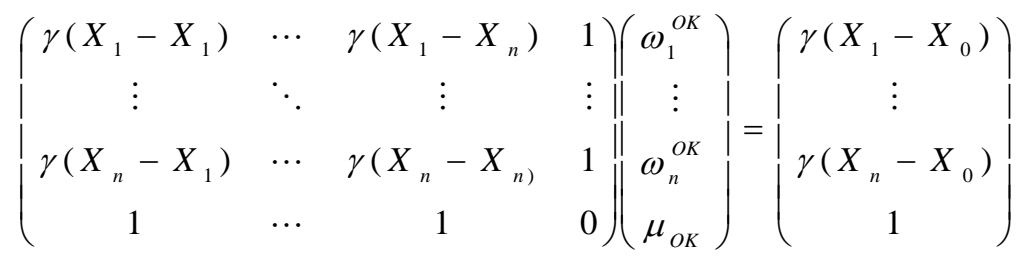

Where the $\omega_{\alpha}^{O K}$ are weights to be assigned to the data values and where $\mu_{O K}$ is the Lagrange parameter. The left hand side of the system describes the dissimilarities between the data points, while the right hand shows the dissimilarities between each data point and the estimation point $\mathrm{X}_{0}$.

Performing the matrix multiplication, the ordinary kriging system can be rewritten in the form:

$$
\left\{\begin{array}{l}
\sum_{\beta=1}^{n} \omega_{\beta}^{\text {OK }} \gamma\left(X_{\alpha}-X_{\beta}\right)+\mu_{O K}=\gamma\left(X_{\alpha}-X_{0}\right) \text { For } \alpha=1, \ldots ., n \\
\sum_{\beta=1}^{n} \omega_{\beta}^{O K}=1
\end{array}\right.
$$

The estimation variance of ordinary kriging is

$$
\sigma_{O K}^{2}=-\mu_{O K}-\gamma\left(X_{0}-X_{0}\right)+2 \sum_{\alpha=1}^{n} \omega_{\alpha}^{O K} \gamma\left(X_{\alpha}-X_{0}\right)
$$

Ordinary kriging is an exact interpolator in the sense that if $\mathrm{X}_{0}$ is identical with a data location then the estimated value is identical with the data value at that point

$$
Z^{*}\left(X_{0}\right)=Z\left(X_{\alpha}\right) \quad \text { if } \mathrm{X}_{0}=\mathrm{X}_{\alpha}
$$

(Including $\mu_{O K}$ ) equal to zero is a solution of the system. As the left hand matrix is not singular, this is the only solution [17].

\section{Indicator Kriging (IK)}

IK uses thresholds to create binary data ( 0 or 1 values), and then uses ordinary kriging to make spatial predictions based on the indicator data. Predictions using indicator kriging are interpreted as the probability of exceeding the specified threshold [12]. IK works as follows.

A series of cut off values (COV) are chosen which are spread through the data values so that they cut the data into a number of groups with ascending values. For example, if the data cover a range of 200 to 1000 , COV may be set at 300, 400, 500, $600,700,800$ and 900, to give 8 groups. The COV need not rise in equal increments. Taking the lowest COV, all data above this receive an indicator value of zero, and those with values equal to or less than the COV receive indicator value of unity, viz.:

$$
Z_{I K}(x)=1 \quad \text { if } Z(x) \leq \mathrm{COV}_{\mathrm{k}}
$$




$$
\mathrm{Z}_{\mathrm{IK}}(\mathrm{x})=0 \quad \text { if } \mathrm{Z}(\mathrm{x})>\mathrm{COV}_{\mathrm{k}}
$$

Where: $\mathrm{Z}_{\mathrm{IK}}(\mathrm{x})$ is the indicator value of the raw data value $\mathrm{Z}(\mathrm{x})$ at location $\mathrm{x}$.

IK is obviously useful for tackling the same problem as Lognormal Kriging (LK) (that is used with highly skewed data), i.e. where the occasional high value occurs in a small set of data [18].

\section{Cross-validation}

To check the suitability of model, cross validation is used. Cross-validation gives an idea of how well the model predicts the unknown values. For all points, cross validation sequentially omits a point, predicts its value using the rest of the data, and then compares the measured with predicted values. The best model is the one that has the mean error nearest to zero, the smallest root-mean-squared error, the average standard error nearest the root-mean-squared error, and the standardized root-mean squared error nearest to one [19].

Summary statistics can be made by comparing the predicted value to the actual value from cross validation.

\section{1 - Mean error}

The equation of mean error is the following:

$$
M_{E}=\frac{\sum_{i=1}^{N}\left\{Z\left(x_{i}\right)_{p}-Z\left(x_{i}\right)_{m}\right\}}{N}
$$

Where: $\mathrm{M}_{\mathrm{E}}$ is the mean error,

$\mathrm{Z}(\mathrm{xi}) \mathrm{p}$ is the predicted value of the sample,

$\mathrm{Z}(\mathrm{xi}) \mathrm{m}$ is the measured value of the same sample,

$\mathrm{N}$ is the number of samples.

2- Root mean squared error

It is derived by squaring the differences between known and unknown points (measured $\&$ predicted), adding those together, dividing that by the number of points, and then taking the square root of that result.

Its formula is given by,

$$
\text { R.M.S.E }=\sqrt{\frac{\sum_{i=1}^{N}\left(Z\left(x_{i}\right)_{p}-Z\left(x_{i}\right)_{m}\right)^{2}}{N}}
$$

3- Average standard error

The standard error is derived by squaring the estimation variances, adding them, dividing by the number of points, and then taking the square root of that result.

The equation for the standard error of the predicted value is:

$$
\text { Std . Error }=\sqrt{\frac{\sum_{i=1}^{n}\left(\sigma\left(x_{i}\right)\right)^{2}}{N}}
$$

4- Mean standardized error

Its formula is given by, 
Stdd . Error $=\frac{\sum_{i=1}^{N}\left(Z\left(x_{i}\right)_{p}-Z\left(x_{i}\right)_{m}\right) / \sigma\left(x_{i}\right)}{N}$

5- Standardized root mean square error

It is derived by squaring the standardized errors, adding them, dividing that by the number of points, and then taking the square root of that result.

Its formula is given by,

Stdd .R.M.S.E $=\sqrt{\frac{\sum_{i=1}^{N}\left[\left(Z\left(x_{i}\right)_{p}-Z\left(x_{i}\right)_{m}\right) / \sigma\left(x_{i}\right)\right]^{2}}{N}}$

\section{THE STUDY AREA}

The study area is Hagaria locality (Figure 1) which is one of five regions in Eastern Mahamid area. This area lies along the right bank of the Nile, to the south of Qena and Luxor, between towns of Esna and Idfu. It is bounded by coordinates latitudes $\left(25^{\circ} 05^{\prime}\right.$ and $\left.25^{\circ} 15^{\prime} \mathrm{N}\right)$ and longitudes $\left(32^{\circ} 32^{\prime}\right.$ and $\left.33^{\circ} 00^{\prime} \mathrm{E}\right)$.

Hagaria locality has an area about $23.38 \mathrm{~km}^{2}$. El-Mahamid deposit is mainly confined to the Upper Cretaceous marine sediments distributed in both the Eastern and Western sides of the Nile Valley. The overlaying Paleocene sediments form the topographic highs, which limit the eastern area from the north and north-west. The Upper Cretaceous sediments are subdivided into two formations, which are, from bottom to top, the Duwi and Dakhla Formations.

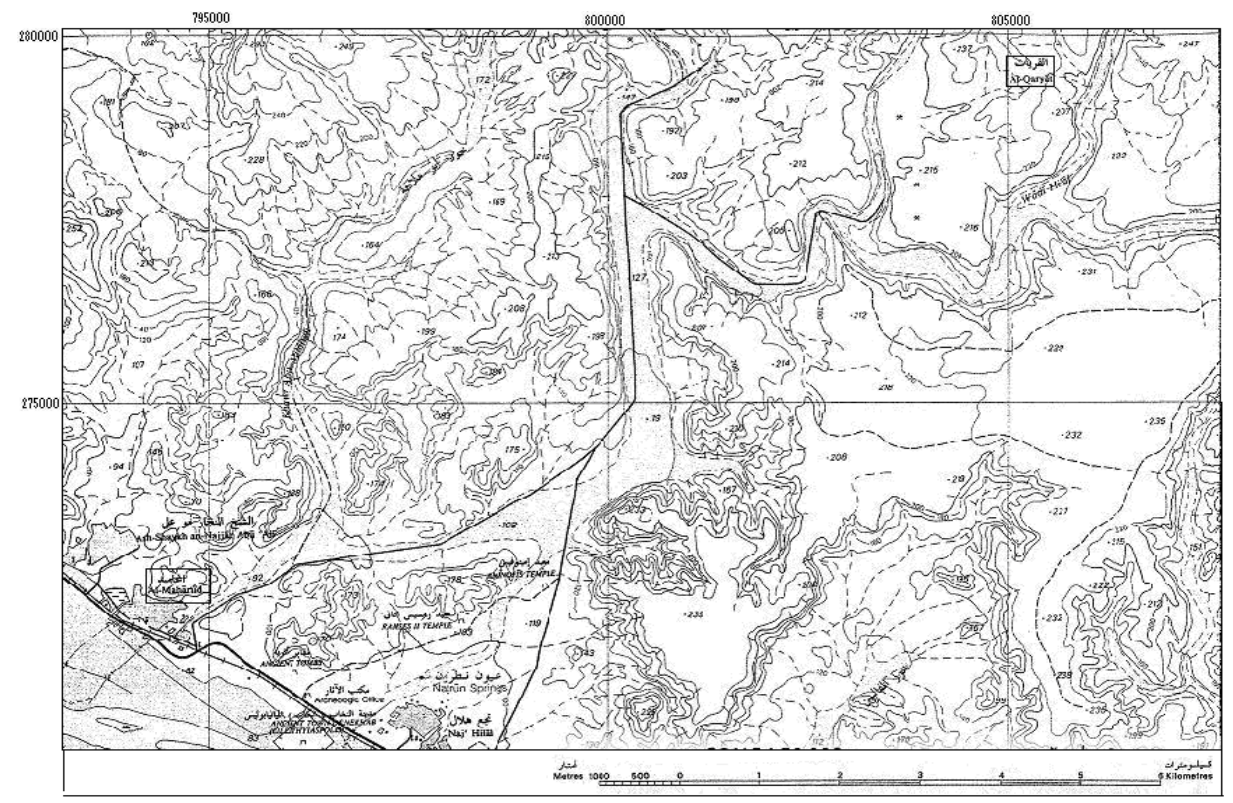

Figure 1: El Mahamid map (E.G.S.A, 1991 [20]). 
The Duwi Formation (Campanian stage) is lithologically subdivided into two sub-formations namely, the Variegated Shales sub-formation $\left(\mathrm{Cr}_{2} \mathrm{VS}\right)$ and the phosphorite sub-formation $\left(\mathrm{Cr}_{2} \mathrm{Ph}\right)$. The important sub-formation is the last one $\left(\mathrm{Cr}_{2} \mathrm{Ph}\right)$, which is subdivided into three members, namely the lower productive carbonate-phosphorite member $\left(\mathrm{Cr}_{2} \mathrm{Ph}_{1}\right)$, middle phosphorite-clayey member $\left(\mathrm{Cr}_{2} \mathrm{Ph}_{2}\right)$ and upper phosphorite-clayey member $\left(\mathrm{Cr}_{2} \mathrm{Ph}_{3}\right)$. The lower productive carbonatephosphorite member $\left(\mathrm{Cr}_{2} \mathrm{Ph}_{1}\right)$, which includes commercial phosphorite beds, is the main object of the investigations carried out in the area. The Dakhla Formation (Maestrichtian stage) does not contain phosphorite intercalation or poor phosphatic marl and limestone [1].

Before conducting any Kriging application, the geological maps of the deposit formation and main structure features such as faults, boundaries and location of the sampling points were collected and fed to the geographic information system as separate layers. Then both $\mathrm{OK}$ and IK techniques have been implemented to krige the two variables under study, $\mathrm{P}_{2} \mathrm{O}_{5} \%$ and thickness of the deposit. Figure 2 illustrates these maps [21].

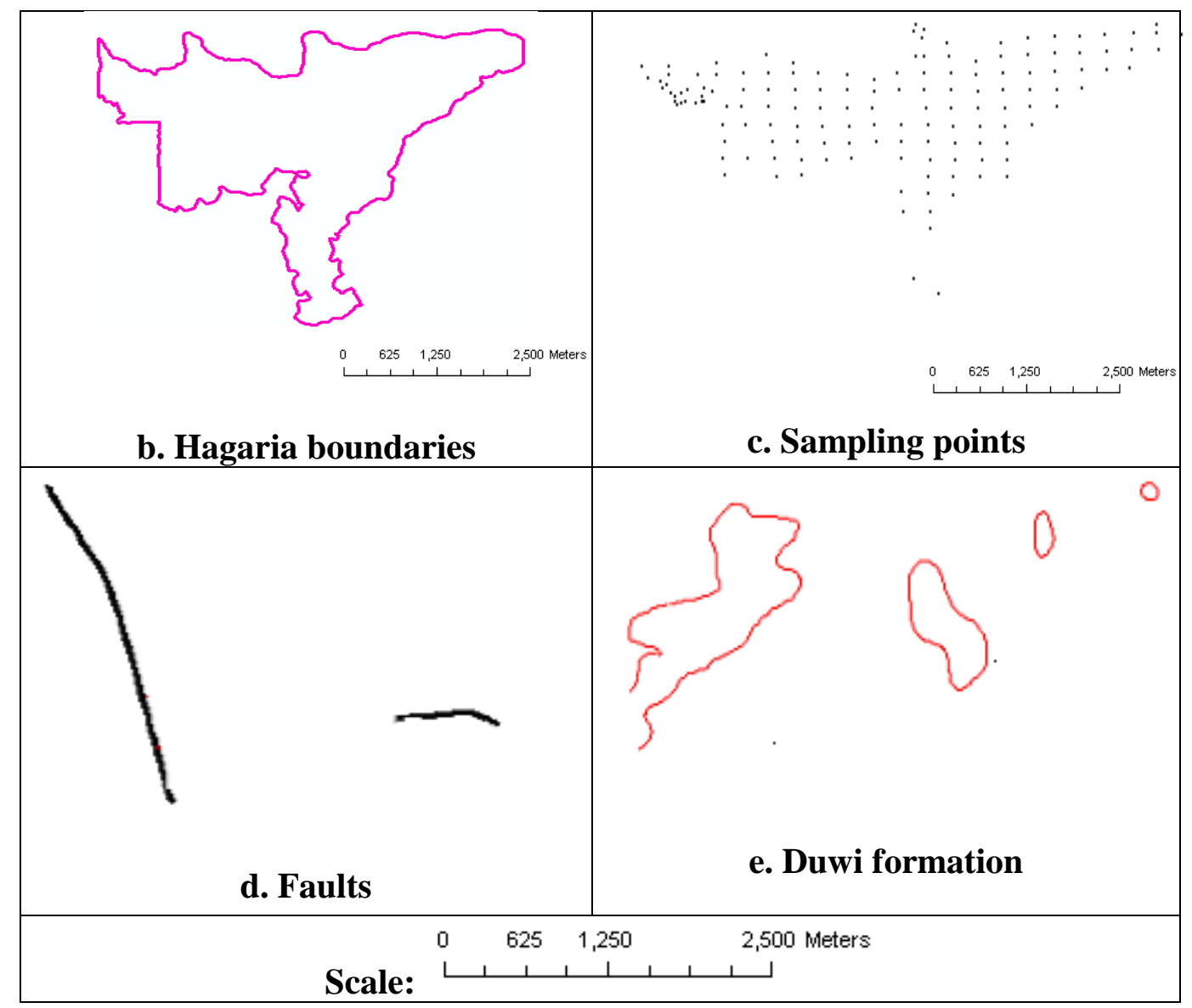

Figure 2: Different maps representing the input layers to GIS system at Hagaria. 


\section{RESULTS AND DISCUSSIONS}

Hundred forty-four samples were collected from different locations in Hagaria area, in order to study and map the spatial distribution of $\mathrm{P}_{2} \mathrm{O}_{5} \%$ and thickness, $\mathrm{X}, \mathrm{Y}$ thickness and $\mathrm{P}_{2} \mathrm{O}_{5} \%$, were recorded at each sampling point. Figure 3 shows the positions of the selected samples.

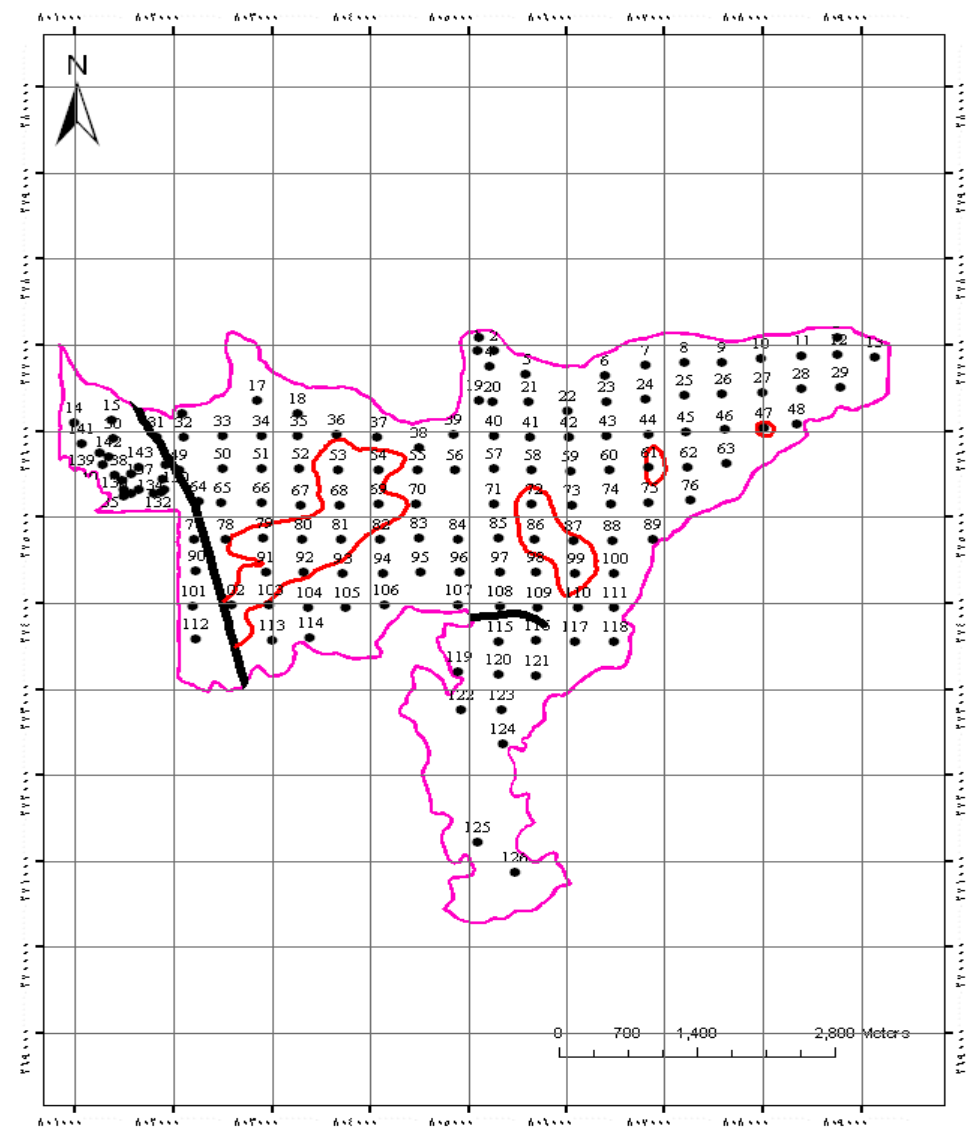

Figure 3: Distribution of the 144 sampling points in Hagaria area.

\section{Descriptive Statistics of $\mathrm{P}_{2} \mathrm{O}_{5} \%$}

This variable has significant effect on the decision maker because it is the most vital component in phosphate industry. The histogram shown in Figure 4.a indicates that the data is uni-modal (one hump) and fairly symmetric. It appears to be close to a normal distribution. As a quick check, if the mean and the median are approximately of the same value, one piece of evidence that the data may be normally distributed. Figure (4.b) shows that data have no clear trend. These figures decide that $\mathrm{OK}$ is the most suitable method for this variable. Table (1) gives the summary statistics of the data sets for $\mathrm{P}_{2} \mathrm{O}_{5} \%$. 


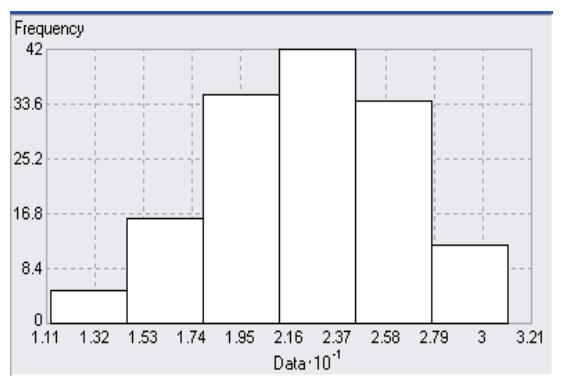

(a) Histogram

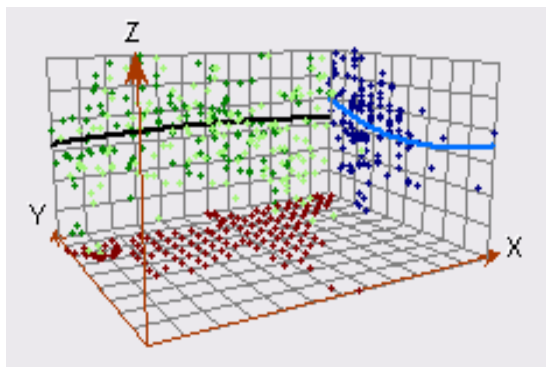

(b) Trend analysis

Figure 4: Summary data analysis of $\mathrm{P}_{2} \mathrm{O}_{5} \%$.

Table 1: Summary statistics of $\mathrm{P}_{2} \mathrm{O}_{5} \%$ in Hagaria area

\begin{tabular}{|l|c|c|c|c|c|c|c|c|}
\hline $\begin{array}{l}\text { Statistical } \\
\text { Parameter }\end{array}$ & $\sum$ & Min. & Max. & Mean & Std & Skw & Kts & Median \\
\hline Raw Data & 144 & 11.28 & 231.1 & 22.36 & 4.217 & -0.311 & 2.901 & 22.75 \\
\hline
\end{tabular}

\section{Geostatistical Analysis}

Figure 5 presents the semivariogram and fitted model for $\mathrm{P}_{2} \mathrm{O}_{5} \%$, and the attributes of the semivariogram for $\mathrm{P}_{2} \mathrm{O}_{5} \%$ were summarized in Table 2 .

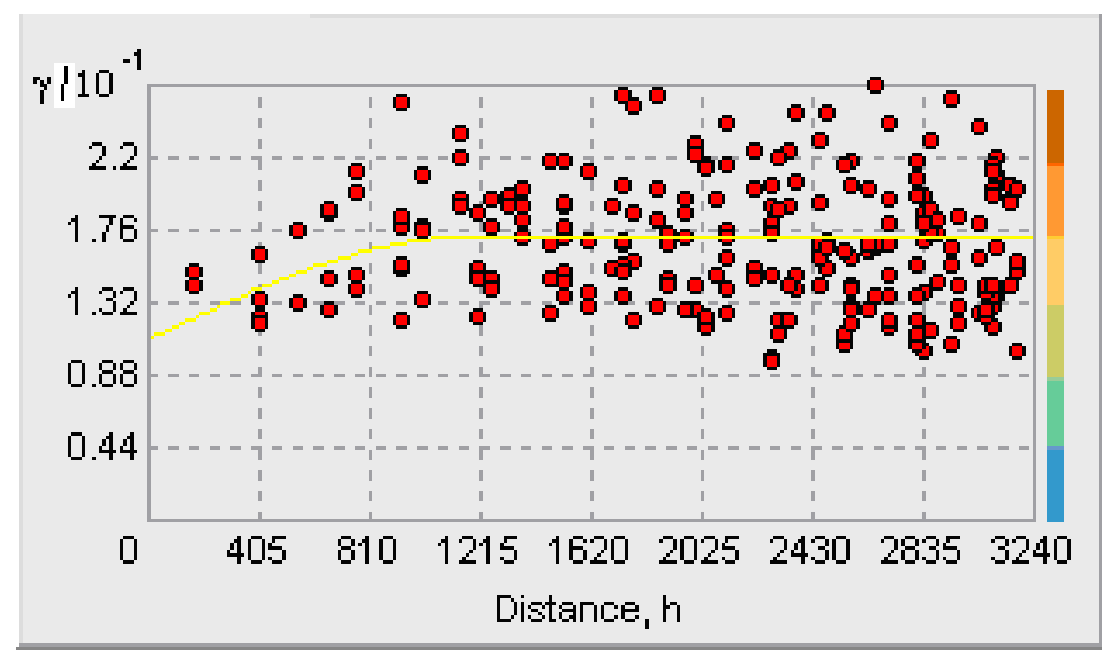

Figure 5: The semivariogram and fitted model of $\mathrm{P}_{2} \mathrm{O}_{5} \%$. 
Table 2: Best fitted semivariogram model of $\mathrm{P}_{2} \mathrm{O}_{5} \%$.

\begin{tabular}{|l|c|}
\hline Parameters of variograms & Value \\
\hline Type & Spherical \\
\hline Direction & Global \\
\hline Range, $m$ & 1187.5 \\
\hline Nugget effect (C0) & 10.96 \\
\hline Sill (C) & 6.28 \\
\hline Lag size & 270 \\
\hline Number of Lags & 12 \\
\hline
\end{tabular}

Where, the best model is the one that has the standardized mean nearest to zero, the smallest root-mean-squared prediction error, the average standard error nearest the root-mean-squared prediction error, and the standardized root-meansquared prediction error nearest to one, therefore, The spherical model realizes all goals of validation of variogram as shown in Table 2. Therefore; it was selected to represent the data. The prediction errors of the ordinary kriging estimates are given in Table 3.

Table 3: Prediction errors of Ordinary Kriging

\begin{tabular}{|l|l|}
\hline \multicolumn{1}{|c|}{ Prediction error } & \multicolumn{1}{c|}{ Value } \\
\hline Mean & 0.0013 \\
\hline Root-mean-square & 3.48 \\
\hline Average standard error & 3.91 \\
\hline Mean standardized & 0.0014 \\
\hline Root-mean-square standardizes & 0.894 \\
\hline
\end{tabular}

The value of mean prediction error $(0.0013)$ being close to zero indicates that the predicted values are unbiased. Similar information is provided by the mean standardized prediction error (0.0014). Also, the average standard error (3.91) is nearest to the root-mean-square of prediction errors (3.48). This shows that our model slightly over-estimates the variability of $\mathrm{P}_{2} \mathrm{O}_{5} \%$. The root-mean square prediction error (or kriging standard deviation) is a measure of the error that occurs when predicting data from point observations and provides the means for deriving confidence intervals for the predictions. Finally, the root-mean-square standardized (0.894) prediction error is very close to one, and thus corresponds to a very good fit between the point estimates of $\mathrm{P}_{2} \mathrm{O}_{5} \%$ and the geostatistical model using Ordinary Kriging.

Figure 6 illustrates the prediction map that introduces regions with different grades of $\mathrm{P}_{2} \mathrm{O}_{5} \%$ by using Ordinary Kriging. The northern part of Hagaria has high different grades, which are $(25-31.1)$ and $(22-25) \mathrm{P}_{2} \mathrm{O}_{5} \%$, except a small portion in the east. The southern part has relatively medium percent (18 to 22) $\mathrm{P}_{2} \mathrm{O}_{5} \%$, the edge in the north-west part on the left of fault is a similar southern part. The yellow colours represent the low grade, which is (11.28-18) $\mathrm{P}_{2} \mathrm{O}_{5} \%$, this percent can not be exploited in the phosphate industry, unless it is blended with other ores of higher grades. 


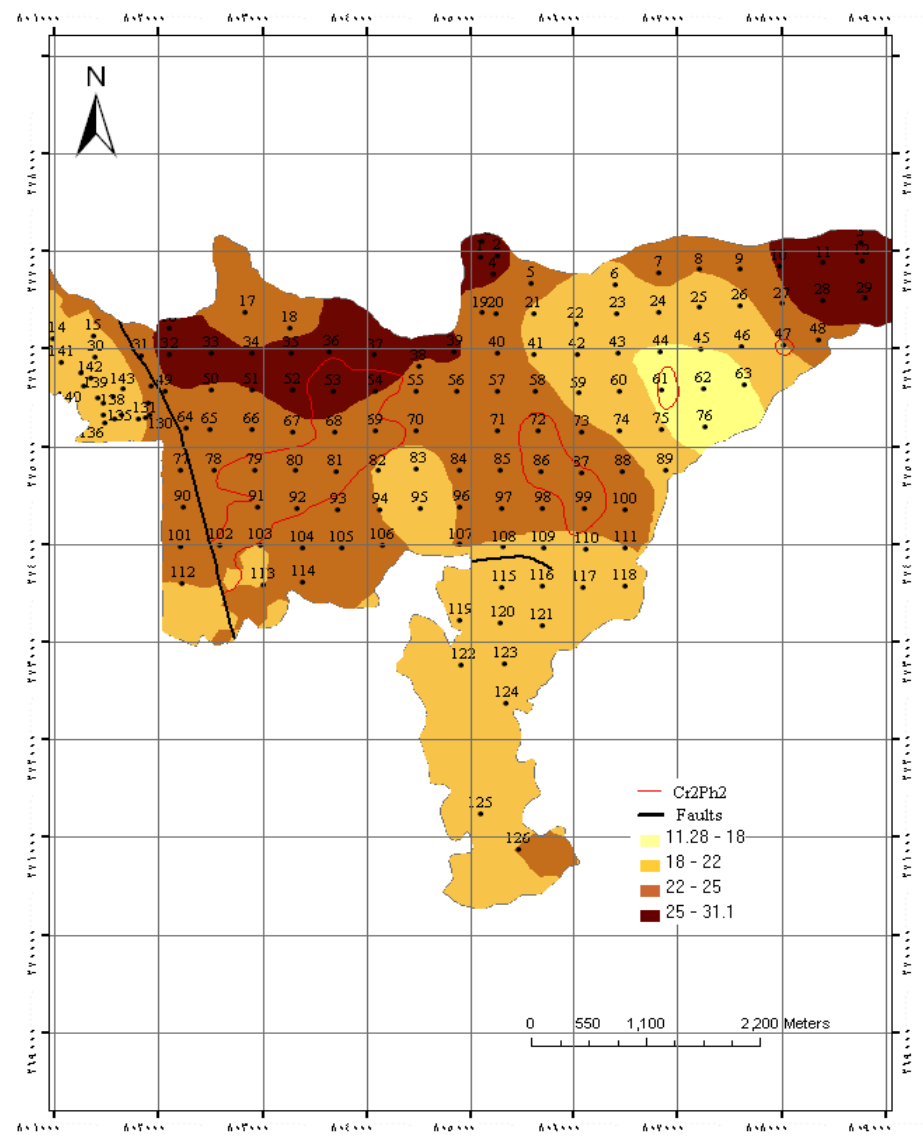

Figure 6: Prediction map of $\mathrm{P}_{2} \mathrm{O}_{5} \%$ of Hagaria ZONE using OK.

\section{2- Descriptive Statistics of Thickness ( $t, m)$}

In this case, the 144 samples of Hagaria area, in order to study and map the spatial distribution of $(\mathrm{t}, \mathrm{m})$, were recorded at each sampling point, and the following is the results of the summary statistics analysis.

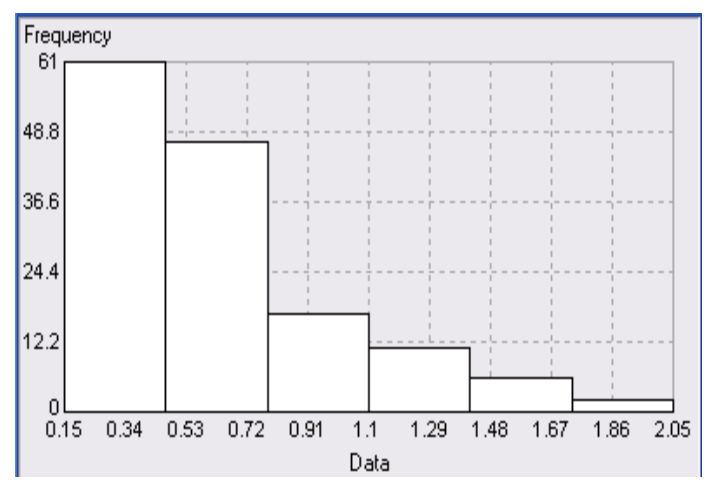

Figure 6: Histogram of data analysis of the thickness $(t, m)$. 
The histogram of the thicknesses data has been performed and Figure 7 shows positive skewed distribution; the most appropriate system of interpolation is Indicator Kriging (IK). Table 4 gives the summary statistics of the data sets for the thickness.

Table 4: Summary statistics of the thickness $(t, m)$ in Hagaria area

\begin{tabular}{|l|c|c|c|c|c|c|c|c|}
\hline Statistical Parameter & $\sum$ & $\mathrm{Mi}$ & $\mathrm{Mx}$ & $\mathrm{Mn}$ & Std & Skw & Kts & Md \\
\hline Raw Data & 144 & 0.15 & 2.05 & 0.637 & 0.379 & 1.39 & 4.69 & 0.55 \\
\hline
\end{tabular}

\section{Geostatistical Analysis}

Spherical model is the best model to fit the data; this is derived from the statistical parameters of cross validation as shown in Table 5.

Table 5: Prediction errors of Indicator Kriging

\begin{tabular}{|l|l|}
\hline \multicolumn{1}{|c|}{ Prediction error } & \multicolumn{1}{c|}{ Value } \\
\hline Mean & 0.000576 \\
\hline Root-mean-square & 0.4355 \\
\hline Average standard error & 0.4393 \\
\hline Mean standardized & 0.00356 \\
\hline Root-mean-square standardizes & 0.986 \\
\hline
\end{tabular}

Figure 8 presents the semivariogram and fitted model for $(t, m)$, and the attributes of the semivariogram for $(\mathrm{t}, \mathrm{m})$ are summarized in Table 6.

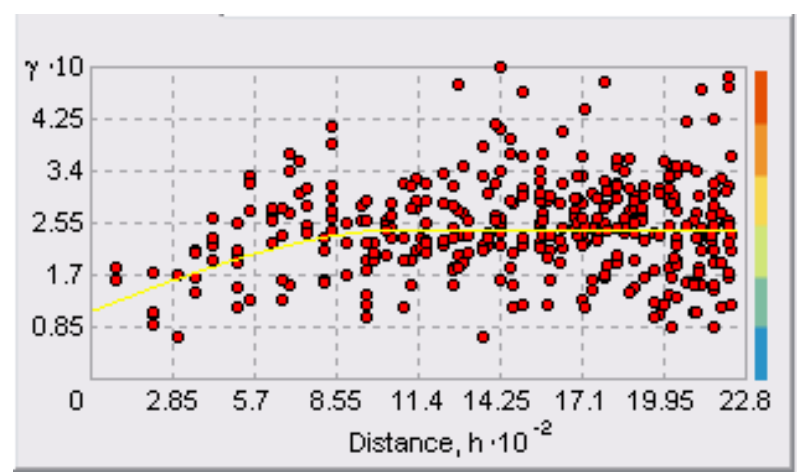

Figure 8: The semivariogram and fitted model of $(t, m)$.

Table 6: Best fitted semivariogram model of $(\mathrm{t}, \mathrm{m})$.

\begin{tabular}{|l|l|}
\hline \multicolumn{1}{|c|}{ Parameters of variogram } & \multicolumn{1}{c|}{ Value } \\
\hline Type & Spherical \\
\hline Direction & Global \\
\hline Range, $m$ & 1104 \\
\hline Nugget effect (C0) & 0.109 \\
\hline Sill (C) & 0.135 \\
\hline Lag size & 150 \\
\hline Number of Lags & 15 \\
\hline
\end{tabular}


Maps have been posted by GIS as shown in Figure 9; from this figure, one can conclude that the left side of the northern part has high thickness beside the fault and the small region in the north-east of area, save for the other places have low thickness relatively. The lowest thickness is represented with yellow colour.

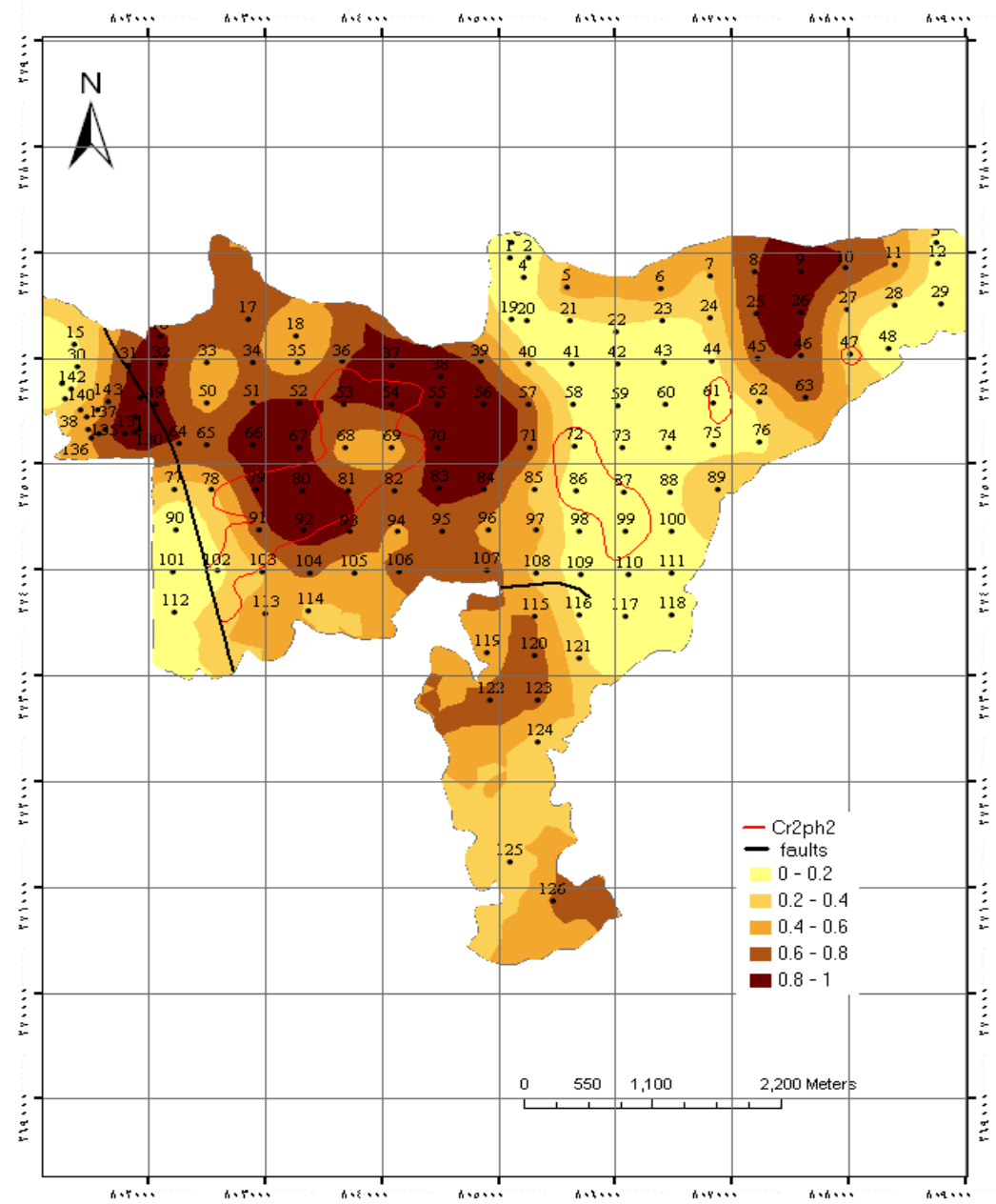

Figure 9: Prediction map of thickness of Hagaria ZONE.

\section{CONCLUSIONS}

An integrated methodology using kriging and GIS has been introduced and implemented over part of El Mahamid area (Hagaria area) to demonstrate the possibility of using the methodology in mapping the spatial distribution of $\mathrm{P}_{2} \mathrm{O}_{5} \%$ and thickness at certain mining area. IK and IK were used to differentiate between the areas with economical mining grades of phosphate and poor ones. In addition, GIS was used to support the visualization of the results and add more information to the kriged results. From the prediction maps of $\mathrm{P}_{2} \mathrm{O}_{5} \%$ and thickness can conclude that the left side of the northern part has high $\mathrm{P}_{2} \mathrm{O}_{5} \%$ and high thickness, therefore the mining engineer start with this economical part at extraction operation. 


\section{ACKNOWLEDGEMENT}

The authors would like to thank the Egyptian Mineral Resources Authority (EMRA) and the people at El Nasr Phosphate Co., for their co-operation and providing the data used throughout this work.

\section{REFERENCES}

[1] Said, R. (1968): "Report on the results of geological exploration at El Mahamid phosphorite deposit", Egyptian General Organization for Geological Research and Mining, pp. 154-173.

[2] Abbady, A. G. E., Uosif, M. A. M., and El-Taher, A., (2005): "Natural radioactivity and dose assessment for phosphate rocks from Wadi El-Mashash and El-Mahamid mines, Egypt", Journal of Environmental Radioactivity, 84, (2005), pp. 65-78.

[3] Abu Ali, M. H., (1987): "Beneficiation of Abu-Tartour phosphate ore with special reference to the minimization of water consumption". MSc. thesis, Mining \& Metallurgical Engineering Department, Faculty of Engineering, Assiut University, Egypt.

[4] Krivoruchko, K. and Gotway, C. A., (2004): "Creating exposure maps using Kriging", Public Health GIS News and Information.

[5] Jones, I., (1998):"A case study using Indicator Kriging — the Mount Morgan gold-copper deposit, Queensland". Perth, Western Australia Proceedings of a symposium held Friday 30th October.

[6] Goovaerts, P., (2000). "Geostatistical approaches for incorporating elevation into the spatial interpolation of rainfall". Journal of Hydrology, 228, pp. 113-129.

[7] Lloyd, C. D., and Atkinson, P. M., (2004): "Increased accuracy of geostatistical prediction of nitrogen dioxide in the United Kingdom with secondary data", International Journal of Applied Earth Observation and Geo-information, 5 (2004), pp. 293-305.

[8] Liu, X.; Wu, J., and Xu, J., (2005): "Characterizing the risk assessment of heavy metals and sampling uncertainty analysis in paddy field by geostatistics and GIS", Environmental Pollution, pp. 1-8.

[9] Yalcin, E., (2001): "Co-Kriging and its effect on the estimation quality" 7th International Conference on Mining, Petroleum and Metallurgical Engineering (MPM). Assiut-Egypt, 10-12 February, Vol. 1, pp. 72-79.

[10] Taboada, J., Vaamonde, A., Saavedra, A., and Ordóñez, C., (2002): "Geostatistical study of the feldspar content and quality of a granite deposit", Engineering Geology 65, pp. 285-292.

[11] Keogh, A. J., and Moulton, C., (1998):"Median Indicator Kriging - a case study in iron ore", Proceedings of a one day Symposium: Beyond Ordinary Kriging. October $30^{\text {th }}, 1998$, Pert, Western Australia. Geostatistical Association of Australia, pp. 106-120.

[12] Potoglou, D., and Kanaroglou, P. S., (2005): "Carbon monoxide emissions from passenger vehicles: predictive mapping with an application to Hamilton, Canada", Transportation Research Part D 10 (2005), pp. 97-109. 
[13] Diodato, N., and Ceccarelli, M., (2004): "Multivariate indicator Kriging approach using a GIS to classify soil degradation for Mediterranean agricultural lands", Ecological Indicators 4, pp. 177-187.

[14] Tsanis, I. K., and Gad, M. A., (2000): "A GIS precipitation method for analysis of storm kinematics", Environmental Modelling \& Software 16 (2001), pp. $273-$ 281.

[15] Watson, W. D., Ruppert, L. F., Bragg, L. J., and Tewalt, S. J., (2001): "A geostatistical approach to predicting sulfur content in the Pittsburgh coal bed", International Journal of Coal Geology, Vol. 48, pp. 1-22.

[16] Burrough P. A., and McDonnell, R. A., (1998): "Principles of geostatistics information system" New York, Oxford University, Inc.

[17] Wackernagel, H., (1995): "Multivariate geostatistics: an introduction with applications", Springer- Verlag Berlin, Heidelberg, Germany.

[18] Royle, A. G., (1992): "A personal overview of geostatistics", Geological Society Special Publication No. 63, pp. 233-241.

[19] An ESRI® white Paper. (2001): "ArcGISTM Geostatistical Analyst: Powerful Exploration and Data Interpolation Solutions". March (2001), USA, 19 P.

[20] Egyptian General Survey Authority and FINNIDA, Finland, (1991): "ALKILH", sheet NG 36 F3b.

[21] Mohamed, H. A. S. (2007): Integrated Methodolgy Using Kriging Geographic Information System to Study the Characteristics of $\mathrm{P}_{2} \mathrm{O}_{5}$ of Mahamid Phosphate, Nile Valley, Egypt. Unpublished MSc. Thesis, Mining and Metallurgical Department, Assiut University, Assiut, Egypt.

\section{استخدام الكريجنج ونظم المعلومات الجغرافية لإلارة استخراج الفوسفات بمنطقة الحجارية،مصر}

يعتبر فهم التوزيـع الفراغي لخامـات الفوسفات وخاصـة توزيـع النسبة المئويـة لخـامس أكسيد الفوسفور وكذلك سمك طبقة الفوسفات من أهم العوامل التي تساعد مهندس التعدين على تحديد أماكن المحتوى

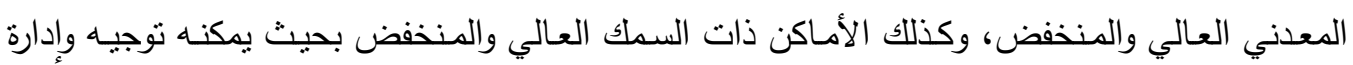
عمليات الاستخراج بنجاح. تتاول هذه الدراسة استخدام طريقتن من طرق الإحصاء الجيولوجي وهي "الكريجنج العادي والكريجنج

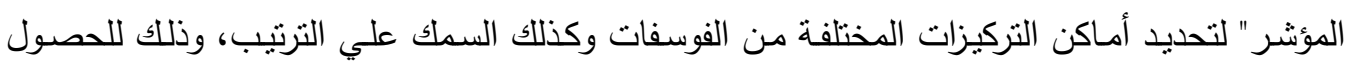

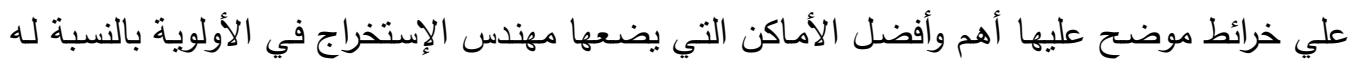

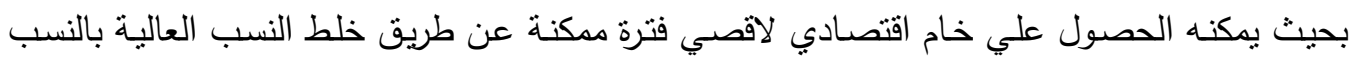

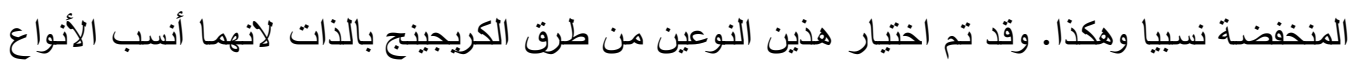

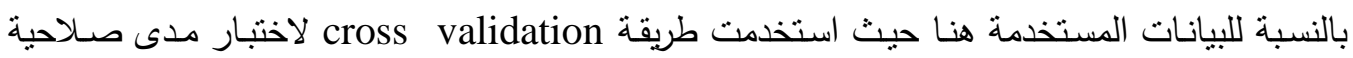

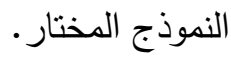


وأجريت هذه الدراسة على منطقة الحجارية (المحاميد الثرقية- مصر ) حيث استخدمت 144 عينة (تم الحصول عليها من هيئة الثروة المعدنية المصرية) معلومة الإحداثيات والمحتوى المعدني من والسمك، واعتبرت القيمة الوسيطة في حالـة الكريجنج المؤشر هي الحد التعديني الاقتصادي الصـالح

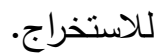
تم دمج نتائج التتبؤ المتحصل عليها من الكريجينج مع قاعدة بيانات ومعلومات جغرافية مصغرة أعدها

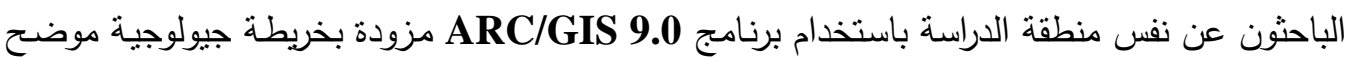

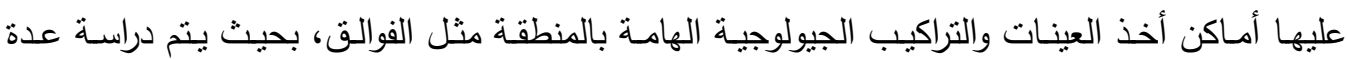

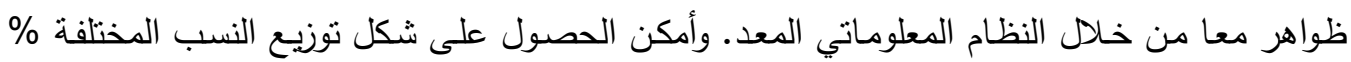
هأ هذا النوزيع ثبين أن أهم جزء في المنطقة هو الجزء الأيسر من الناحية الثمالية للمنطقة حيث إنه يحتوي

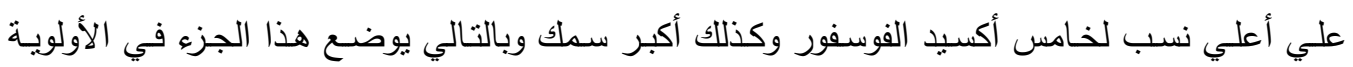

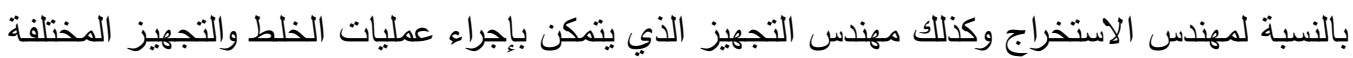
من الاستفادة بأغلب المناطق الموجودة. إن إعداد مثل هذه الخرائط سوف يساعد مهندس التعدين علي اتخاذ القرارات السليمة المؤدية إلى تحقيق المكاسب الاقتصادية, وبالتالي فقد ربطنا بين نظم المعلومات الجغرافية وبين الكريجنج، بحيث نقدم صورة متكاملة لمنطقة الدراسة بتسهيلات أفضل. 